\title{
INSULATION TESTING USING CRYOSTAT APPARATUS WITH SLEEVE
}

\author{
J. E. Fesmire ${ }^{1}$ and S. D. Augustynowicz ${ }^{2}$ \\ ${ }^{1}$ NASA Kennedy Space Center, MM-J2 \\ Kennedy Space Center, FL 32899, USA \\ ${ }^{2}$ Dynacs Engineering Company, Inc., DNX-3 \\ Kennedy Space Center, FL 32899, USA
}

\begin{abstract}
The method and equipment of testing continuously rolled insulation materials is presented in this paper. Testing of blanket and molded products is also facilitated. Materials are installed around a cylindrical copper sleeve using a wrapping machine. The sleeve is slid onto the vertical cold mass of the cryostat. The gap between the cold mass and the sleeve measures less than $1 \mathrm{~mm}$. The cryostat apparatus is a liquid nitrogen boiloff calorimeter system that enables direct measurement of the apparent thermal conductivity (k-value) of the insulation system at any vacuum level between $5 \times 10^{-5}$ and 760 torr. Sensors are placed between layers of the insulation to provide complete temperature-thickness profiles. The temperatures of the cold mass [maintained at 77.8 kelvin $(\mathrm{K})$ ], the sleeve [cold boundary temperature (CBT)], the insulation outer surface [warm boundary temperature (WBT)], and the vacuum can (maintained at $313 \mathrm{~K}$ by a thermal shroud) are measured. Plots of CBT, WBT, and layer temperature profiles as functions of vacuum level show the transitions between the three dominant heat transfer modes. For this cryostat apparatus, the measureable heat gain is from 0.2 to 20 watts. The steady-state measurement of $\mathrm{k}$-value is made when all temperatures and the boiloff rate are stable.
\end{abstract}

\section{INTRODUCTION}

The advantages of using cryogen boiloff calorimeters for measuring the thermal performance of insulation systems assembled in a cylindrical manner have been previously described. ${ }^{1,2,3}$ The main challenge in the execution of this technique is to obtain stability of the cryogen inside the three chambers coincident with stability of the boundary conditions in the vacuum space. That is, the liquid inside each of the three chambers of the cold mass must be brought to very near saturated conditions at the ambient pressure while the vacuum level and temperatures across the insulation thickness are maintained at constant values. The main problem with testing high performance materials such as multilayer insulation 
(MLI) is the extreme care that must be exercised in the fabrication and installation of such highly anisotropic test articles. As emphasized by De Haan ${ }^{4}$, inconsistency in MLI wrapping techniques is the dominant source of error and poses a basic problem in the comparison of such insulating materials. Improper treatment of the ends or seams, for example, can render a measurement that is several times worse than predicted. Localized compression effects, sensor installation, and outgassing are further complications. To eliminate the seam and minimize these other problems, a sleeve method of fabricating and testing insulation has been developed. The improved method and corresponding equipment for testing continuously rolled materials are the subject of this paper.

\section{DESCRIPTION OF TEST EQUIPMENT}

The cryostat apparatus, shown in Figure 1, is a sleeved liquid nitrogen boiloff calorimeter that enables direct measurement of the apparent thermal conductivity (k-value) of the insulation system at a vacuum level between $5 \times 10^{-5}$ and 760 torr. The cryostat cold mass is a $167-\mathrm{mm}$-diameter by $900-\mathrm{mm}$-long cylinder constructed from heavy-wall stainless steel which provides high thermal stability. The cold mass consists of a 10-liter capacity test chamber with 2.5 -liter (each) guard chambers on top and bottom over which the instrumented, insulated sleeve is installed. A removable vacuum can allows quick changeover of test articles. The apparatus is supplied with liquid nitrogen, subcooled to approximately $77.8 \mathrm{~K}$, as depicted in the simplified system schematic of Figure 2 . The measurable total heat transfer rate is from 0.2 to 20 watts, corresponding to a boiloff flow rate of from 50 to 5000 cubic centimeters per minute of gas at standard temperature and pressure. The vacuum pumping system consists of a combination of turbopumps and mechanical pumps plus a finely metered gaseous nitrogen supply to control pumping speed.

In testing, five operational sequences are performed: (1) heating and vacuum pumping, (2) liquid nitrogen cooling and filling, (3) cold soak, (4) replenish boiloff, and (5) steady-state boiloff. Steady-state conditions are typically achieved in less than 12 hours after an initial cooling and thermal stabilization period of at least 24 hours. During the boiloff replenish phase, the guard chambers are maintained at approximately $4.0 \pm 1 \mathrm{kPa}$. In the final phase, liquid nitrogen replenish of the guard chambers is terminated as the cold mass approaches thermal equilibrium at near ambient pressure saturated conditions. The upper guard chamber is kept at a slightly higher pressure $(1.0 \pm 0.3 \mathrm{kPa})$ than the test chamber to preclude the condensation of any boiloff gas as it exits through the center of the guard.

Materials are installed around a cylindrical copper sleeve using the custom-built 1meter wide wrapping machine shown in Figure 3. Testing of blanket, loose fill, poured, and molded products is also facilitated by this sleeve method. Insulation test articles 170 $\mathrm{mm}$ inside diameter by $900 \mathrm{~mm}$ in length by up to $50 \mathrm{~mm}$ in thickness can be fabricated and tested. Using an effective length of the cold mass of $575 \mathrm{~mm}$, the mean surface area for heat transfer through a typical $25-\mathrm{mm}$-thick insulation test article is $0.35 \mathrm{~m}^{25}$. After fabrication of the insulation system, the sleeve is simply slid onto the vertical cold mass of the cryostat. The gap between the cold mass and the sleeve measures less than $1 \mathrm{~mm}$. Sensors are placed between layers of the insulation to obtain complete temperature-thickness profiles. Temperatures of the cold mass (maintained at near $77.8 \mathrm{~K}$ ), the sleeve $(\mathrm{CBT})$, the insulation outer surface (WBT), and the vacuum can (maintained at near $313 \mathrm{~K}$ by thermal shroud) are measured as shown in Figure 4.

The steady-state measurement of insulation performance is made when all temperatures and the boiloff flow are stable. The k-value of the insulation is directly determined from the measured boiloff rate, temperature difference (WBT-CBT), latent heat of vaporization, and geometry of the insulation. All measurements are recorded on a custom built 32-channel data acquisition system using LabView software. 


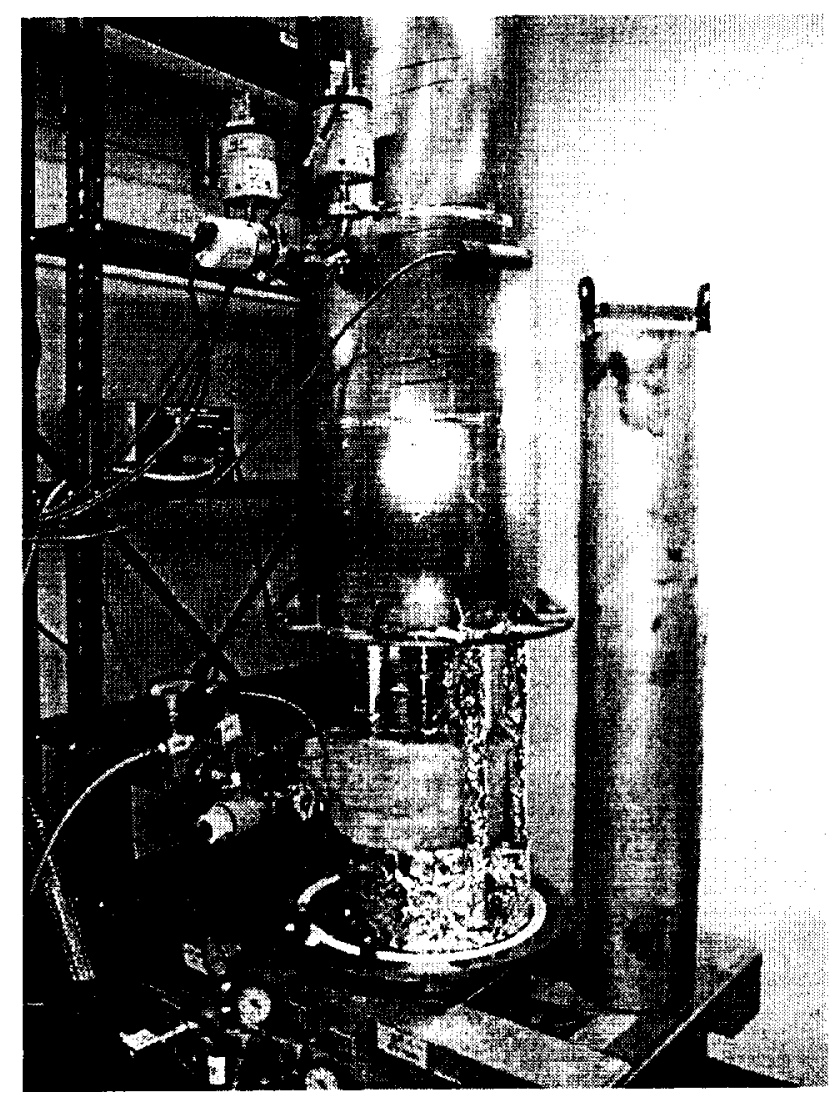

Figure 1. Cryostat test apparatus showing the insulation test article inside (extra sleeve shown for reference).

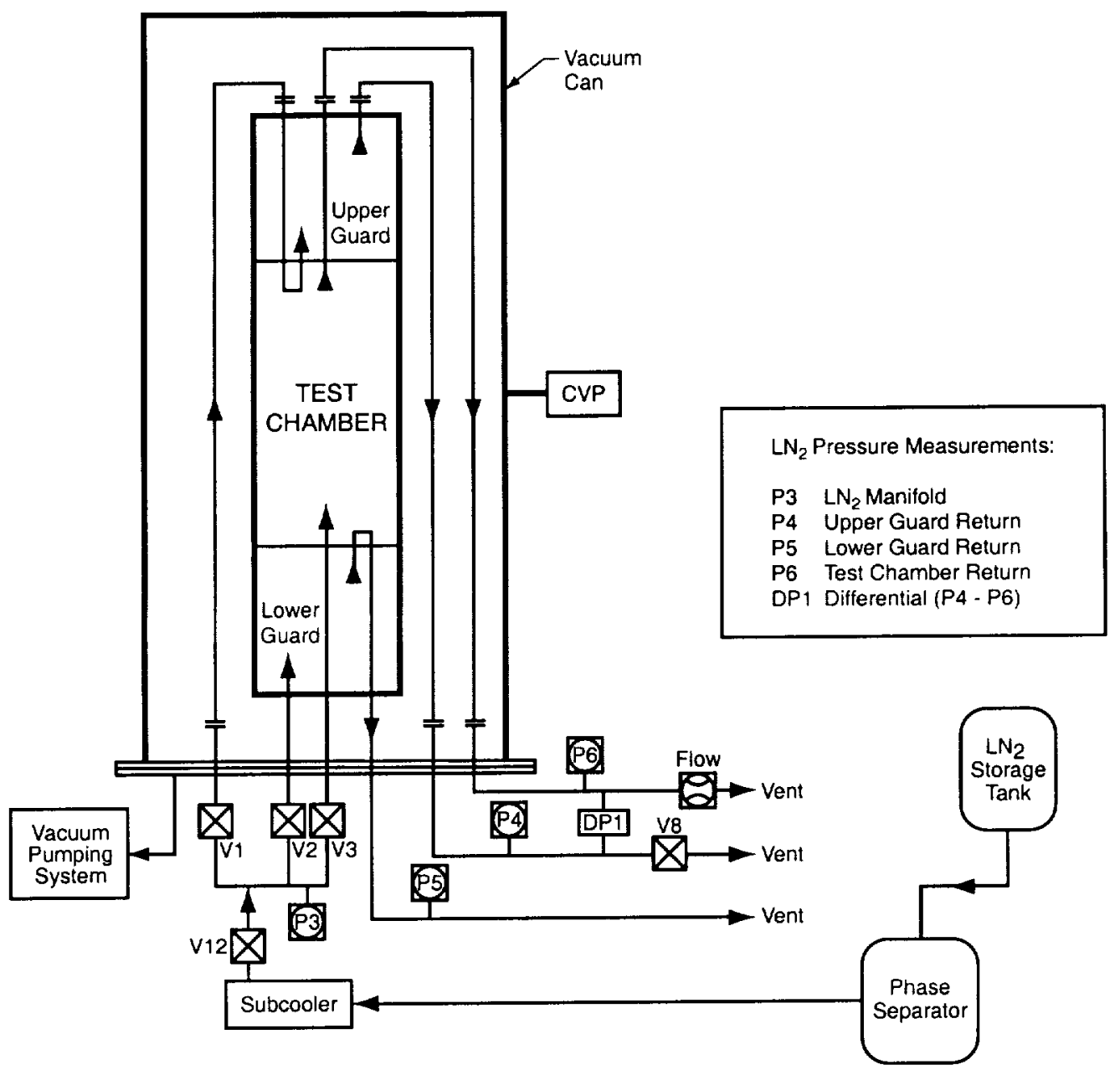

Figure 2. Simplified schematic of the cryostat test apparatus indicating key system measurements. 


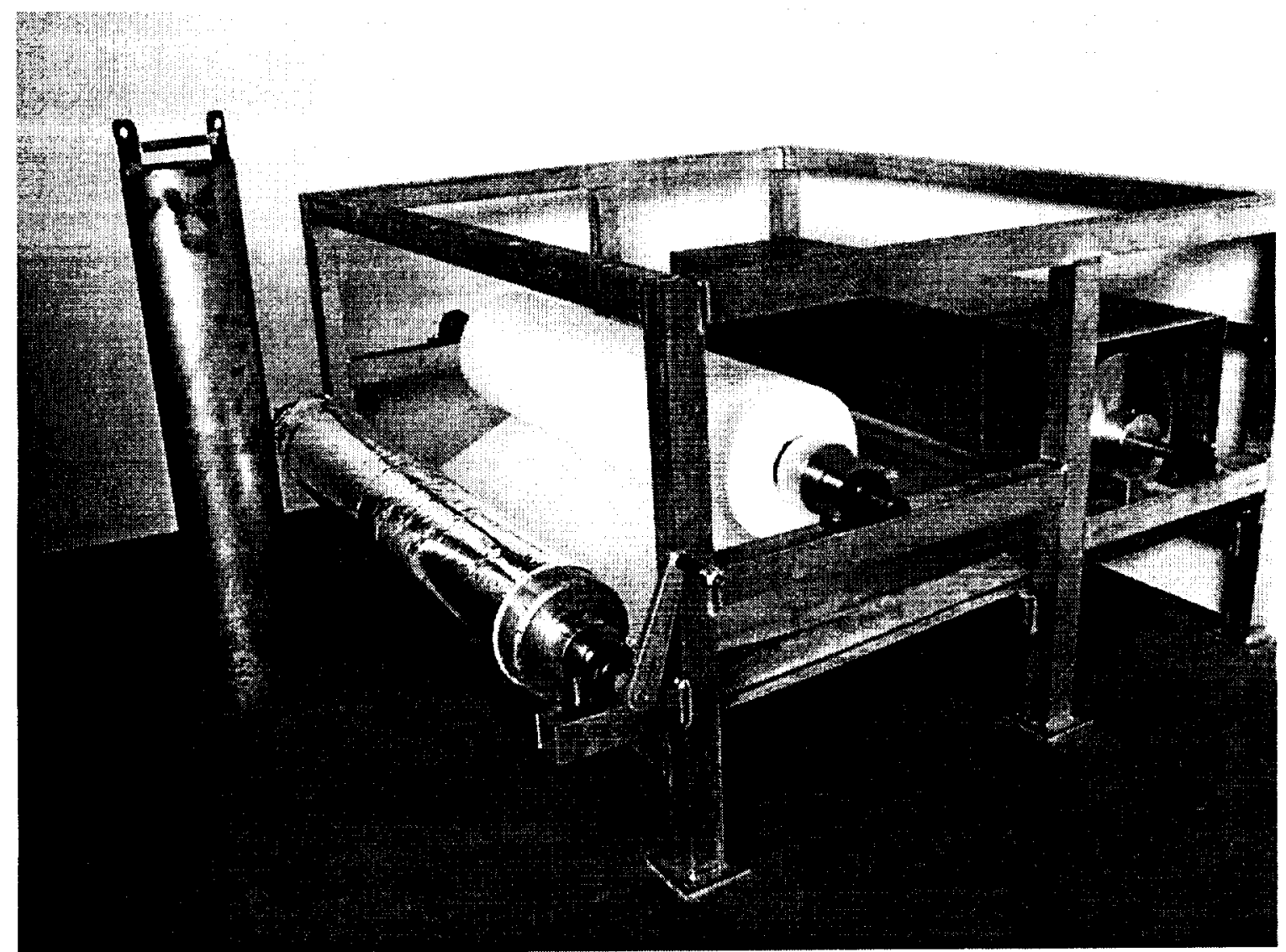

Figure 3. Multilayer insulation wrapping machine and copper sleeve assembly.

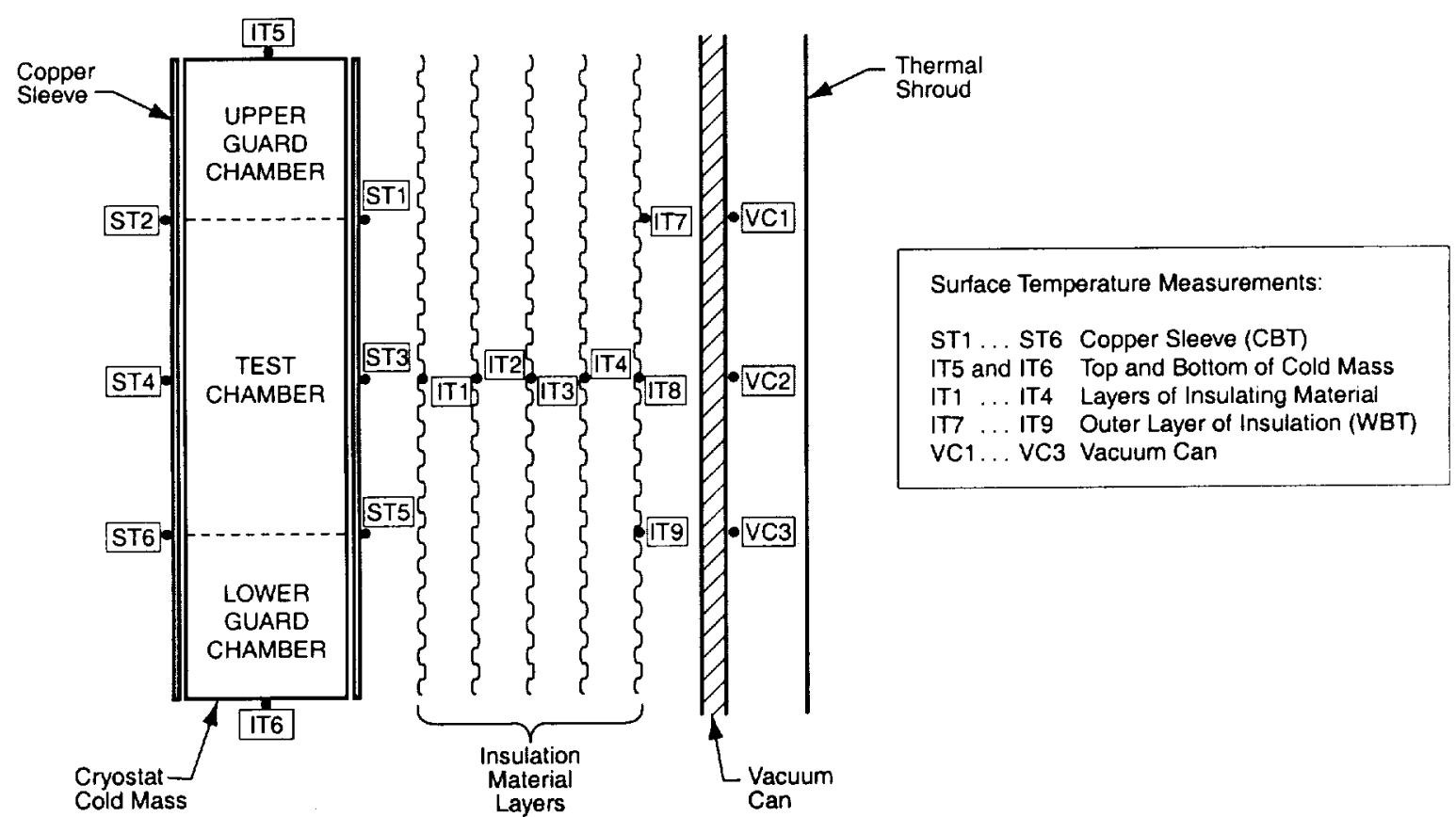

Figure 4. Diagram of temperature sensor locations for a typical insulation test configuration. 


\section{MEASUREMENT SUMMARY}

Accurate measurements require repeatable and precise operation of each element of the total system. Boiloff measurements in the milliwatt range require long stabilization times and a carefully executed process to achieve thermal stability. This stability comes about through reaching a saturated liquid condition inside the test chamber that precisely matches the guard chambers. Tests at cold vacuum pressure (CVP) above 0.1 torr are further complicated by the influence of viscous gas conduction and convection which hinder maintaining constant boundary temperatures and a fixed vacuum level. The four charts of Figure 5 give a summary of the key system parameters for a typical test (including cold soak, replenish boiloff, and steady-state boiloff) of an evacuated insulation system. ${ }^{6}$

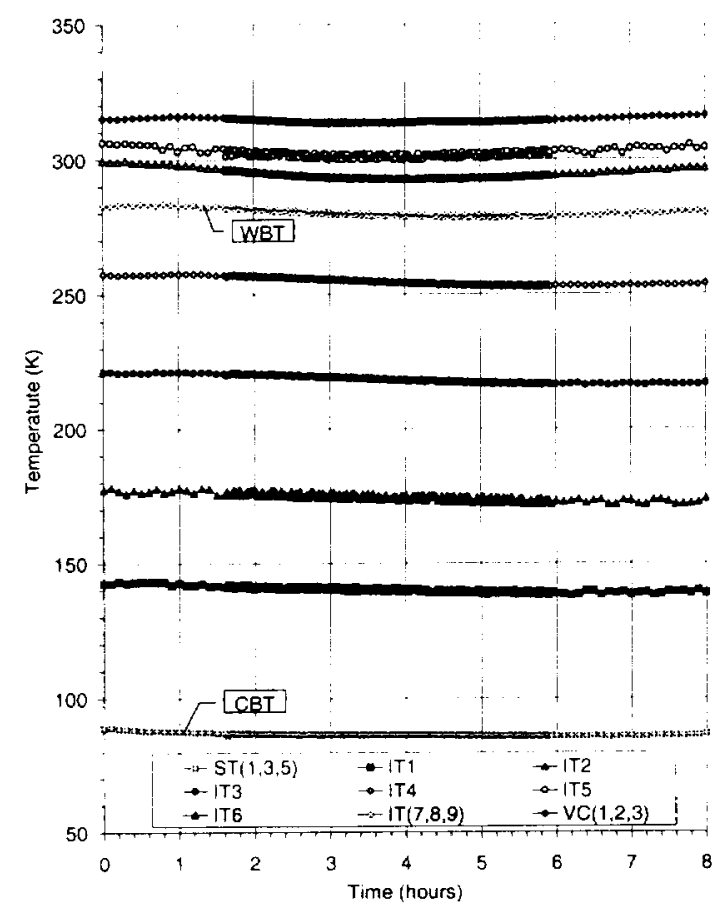

(a)

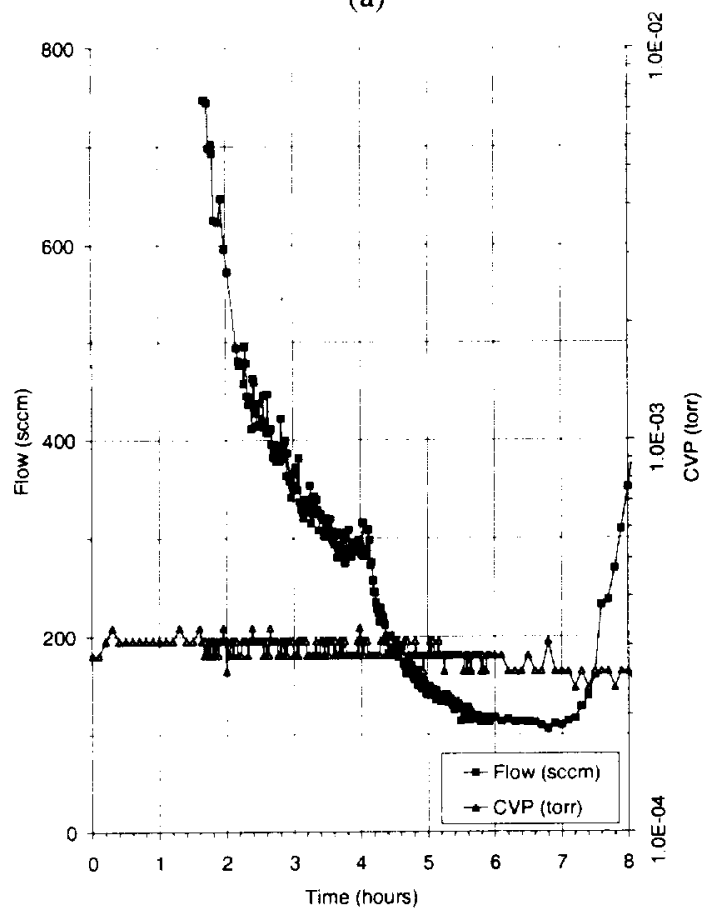

(c)

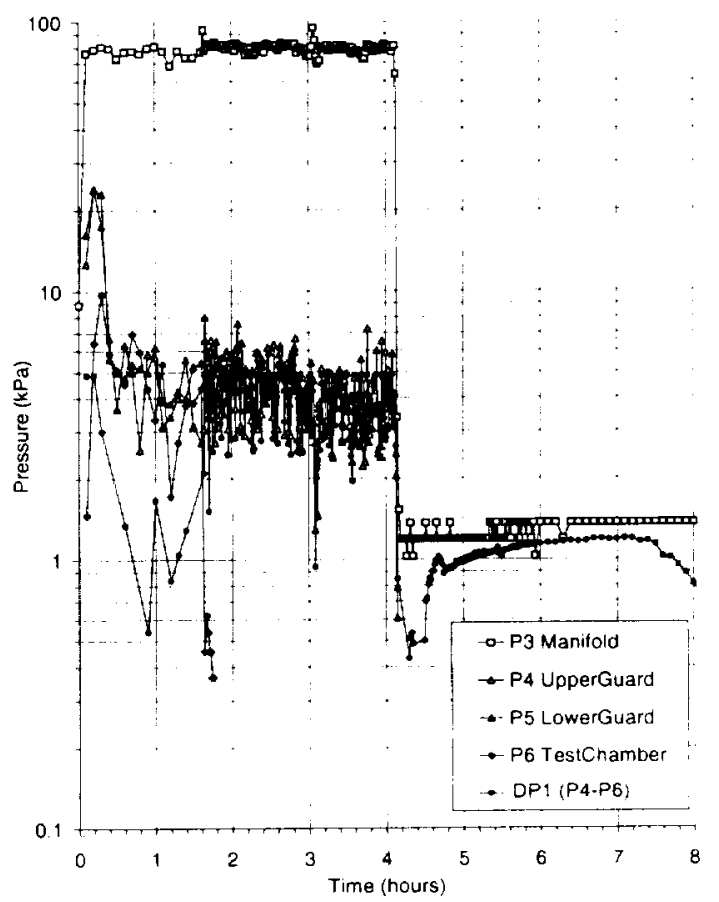

(b)

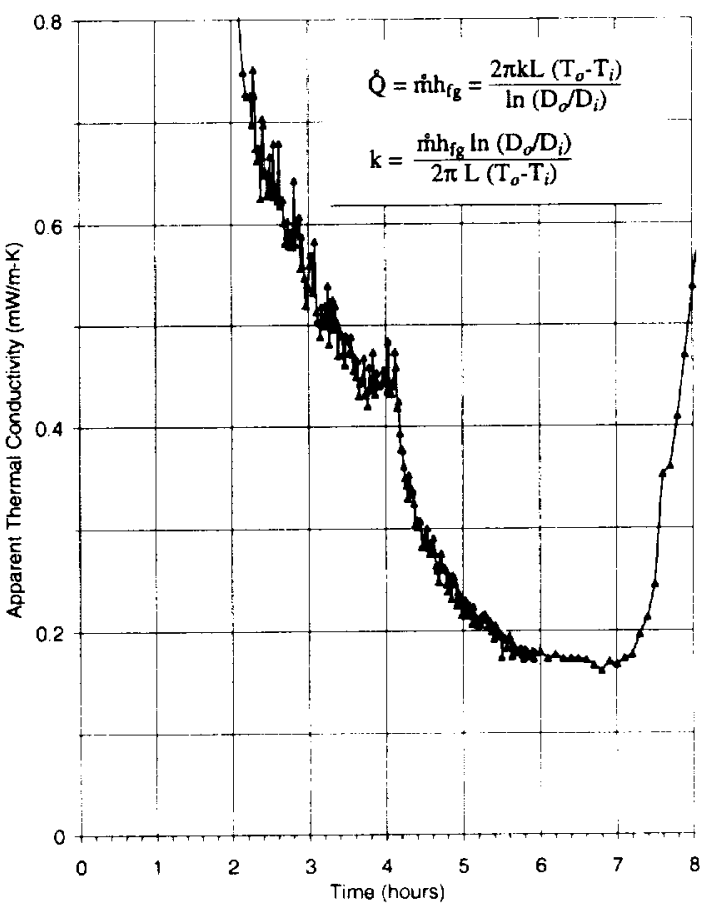

(d)

Figure 5. Test measurements for a typical evacuated insulation system: (a) layer temperature distribution, (b) chamber $\mathrm{LN}_{2}$ pressures, (c) boiloff flow and CVP, and (d) calculated k-value. 


\section{SLEEVE GAP EFFECTS}

A series of boiloff tests with only the sleeve installed was performed to understand the effects of the gap between the sleeve and cold mass on the thermal stability of the system. The temperature profiles in Figure 6(a) clearly show the transition from radiation to gasconduction-dominated heat transfer. Observations showed another transition to convection-dominated heat transfer at about 40 torr. Apparent thermal conductivity values for the gap and the vacuum space are given in Figure 6(b). The measured k-values at the $10^{-4}$ torr level correspond to typical experimental values for unpolished surfaces. Reported values for a pure vacuum insulation system range from about 0.5 to $5 \mathrm{~mW} / \mathrm{m}-\mathrm{K}$ for boundary temperatures of 300 and $77 \mathrm{~K}$, depending on the emissivities of the surfaces.

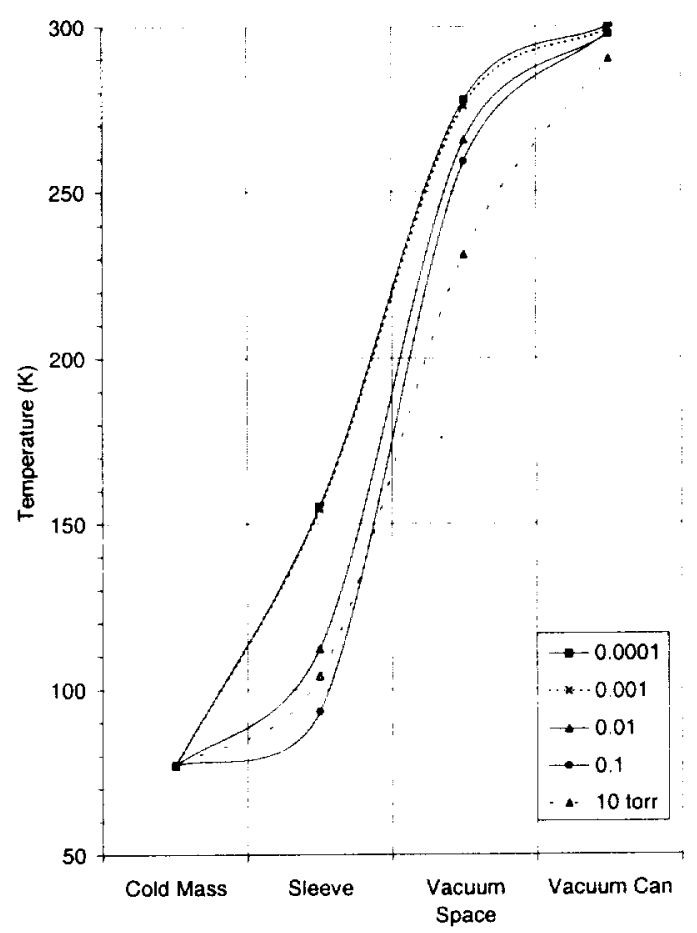

(a)

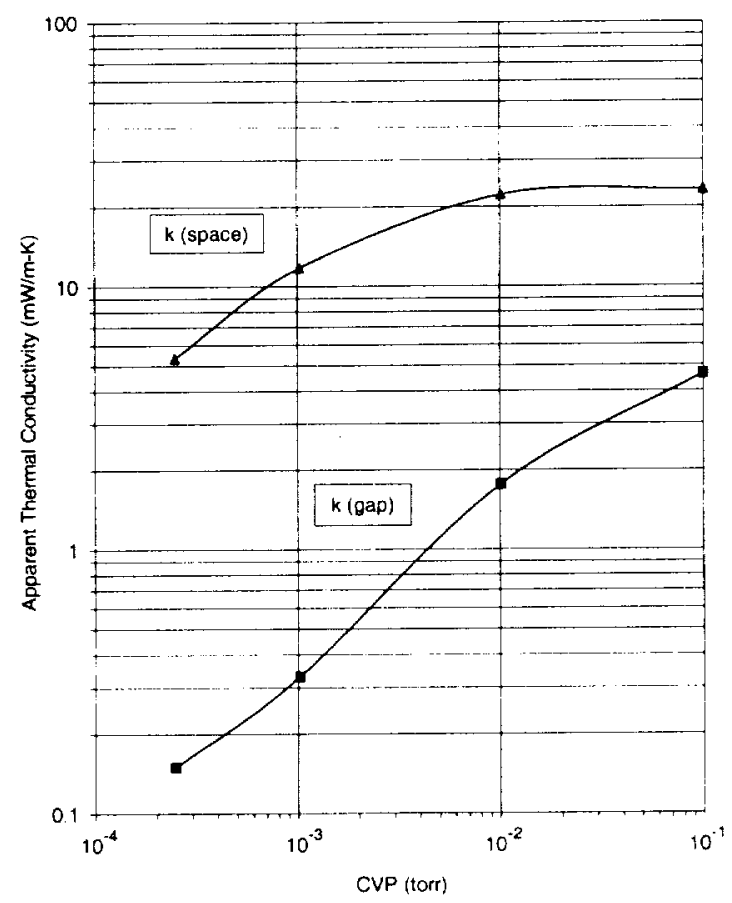

(b)

Figure 6. Tests with the sleeve only: (a) temperature profiles and (b) k-values as a function of CVP. 


\section{BOUNDARY TEMPERATURE EFFECTS}

Variations of the warm and cold boundary temperatures with CVP are shown for selected insulation test articles in Figure $7 .^{6}$ The influence of gas conduction can be clearly seen starting at $10^{-3}$ torr with a minimum CBT reached at $10^{-1}$ torr. The temperature sensors used were thermocouples with standard reference junctions. Overall trends, not individual accuracy, are therefore emphasized. The vacuum can temperature (thermal shroud) was maintained at approximately $313 \mathrm{~K}$ in order to obtain a WBT of about $290 \mathrm{~K}$ for most insulations over the widest range of vacuum levels. In contrast, detailed studies of a single insulation system would be conducted by keeping the WBT at a prescribed value.

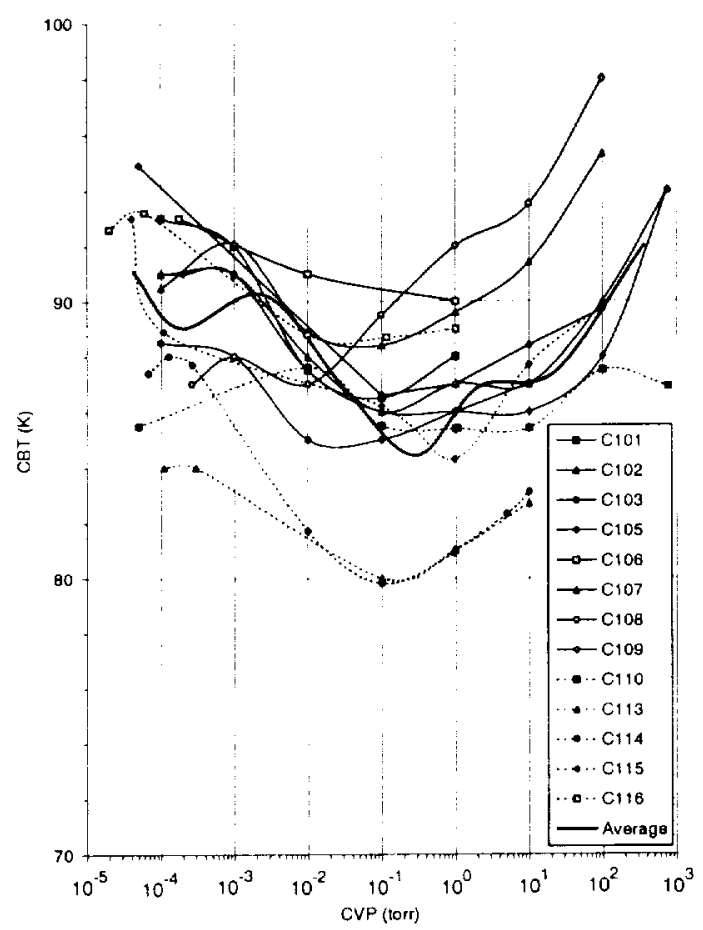

(a)

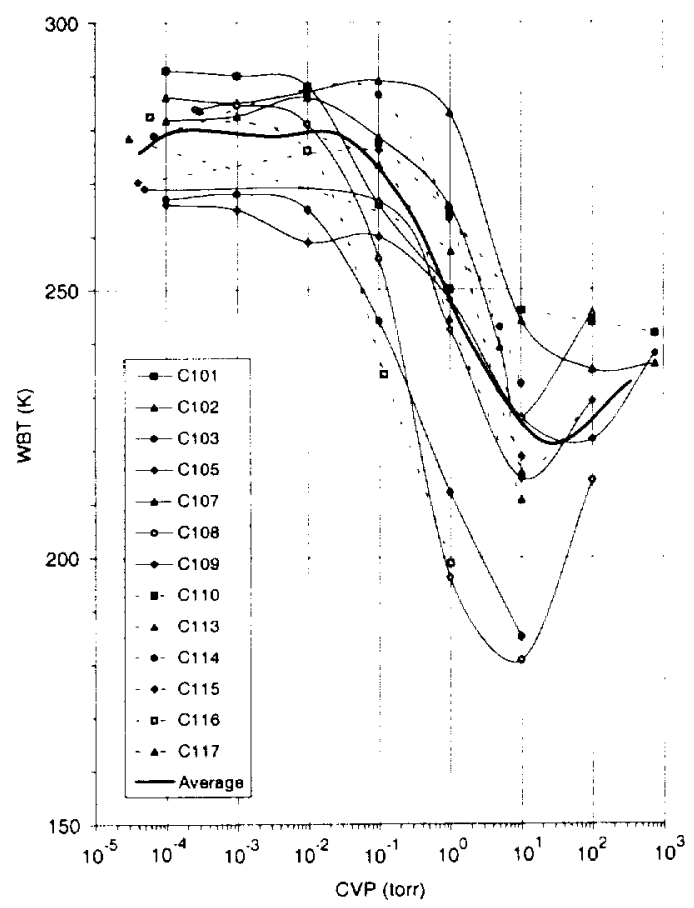

(b)

Figure 7. Variation of boundary temperatures with CVP for selected insulations: (a) CBT and (b) WBT. 


\section{CONCLUSIONS}

An improved method of testing cryogenic insulation systems using a sleeve for insulation fabrication and test on a cylindrical boiloff calorimeter has been developed. The sleeve method is particularly useful for multilayer insulation test and evaluation by eliminating the error inherent with seams and reducing other problems with fabrication and handling. The sleeve allows test articles to be fabricated off-site and facilitates the testing of almost any product form. The corresponding wrapping method for continuously rolled products offers convenience in fabrication, installation, and instrumentation while providing a precise, repeatable process with no handling of the materials required. Over 150 tests of 18 different test articles have been performed that demonstrated the measurement range of the system. ${ }^{6}$ Boundary temperatures are in the range of 80 to $300 \mathrm{~K}$. The sleeve method can be used for vacuum levels up to 760 torr for comparative results but should be limited to about 10 torr for accurate quantitative results.

A smaller boiloff apparatus with a fully removable cold mass has recently been built to address these limitations. This system, a calibrated-type cryostat, can support testing at a rate of up to five cylindrical test articles per week. The cold mass can also be configured for flat plate insulation geometries to test compression effects in MLI or to test smaller size samples. Optimization studies, for example, may be performed, followed by tests using the larger cryostat for the final performance measurements. Both cryostats are presently being used in thermal insulation studies and applications development in the Cryogenics Test Laboratory at NASA Kennedy Space Center.

\section{REFERENCES}

1. S.L. Bapat, K.G. Narayankhedkar, and T.P. LuKose, Experimental investigations of multilayer insulation, Cryogenics, Vol. 30, 1990, pp. 711-719.

2. R.M. Coston and C.A. Zierman, Cryogenic thermal-conductivity measurements of insulating materials, Thermal-Conductivity Measurements of Insulating Materials at Cryogenic Temperatures, ASTM STP 411, American Society for Testing Materials, 1967, pp. 25-42.

3. M.G. Kaganer, Thermal Insulation in Cryogenic Engineering, Israel Program for Scientific Translations Ltd., Israel, 1969.

4. J.R. De Haan, A simple multilayer insulation calorimeter, Thermal Conductivity Measurements of Insulating Materials at Cryogenic Temperatures, ASTM STP 41 1, American Society for Testing Materials, 1967, pp. 95-109.

5. ASTM C 745, Standard test method for heat flux through evacuated insulations using a guarded flat plate boiloff calorimeter, American Society for Testing Materials, 1992.

6. S.D. Augustynowicz and J.E. Fesmire, Cryogenic insulation system for soft vacuum, Cryogenic Engineering Conference, Montreal, 1999.

7. T.M. Flynn, Cryogenic Engineering, Marcel Dekker, New York, 1997, pp. 440-441. 